\title{
Modeling and Simulation of a Cracked Beam with Different Location Using FEM
}

\author{
Rajib Karmaker ${ }^{1}$, Ujjwal Kumar Deb ${ }^{2 *}$, Amrita Das $^{3}$ \\ ${ }^{1}$ Department of Mathematics, Premier University, Chattogram, Bangladesh \\ ${ }^{2}$ Department of Mathematics, Chittagong University of Engineering and Technology, Chattogram, Bangladesh \\ ${ }^{3}$ Department of Civil Engineering, Southern University Bangladesh, Chattogram, Bangladesh \\ Email: rajibcumath@gmail.com, *ukdebmath@cuet.ac.bd, amritadascuet@gmail.com
}

How to cite this paper: Karmaker, R., Deb, U.K. and Das, A. (2020) Modeling and Simulation of a Cracked Beam with Different Location Using FEM. Computational Water, Energy, and Environmental Engineering, 9, 145-158.

https://doi.org/10.4236/cweee.2020.94010

Received: August 24, 2020

Accepted: October 17, 2020

Published: October 20, 2020

Copyright $\odot 2020$ by author(s) and Scientific Research Publishing Inc. This work is licensed under the Creative Commons Attribution International License (CC BY 4.0).

http://creativecommons.org/licenses/by/4.0/

\begin{abstract}
Nowadays presence of crack in different engineering structures becomes a serious threat to the performance. Since most of the civil and mechanical structures may be damaged due to material fatigue, mechanical vibration, environmental attack and long-term service. Moreover, dynamical systems of a beam usually possess a non-linear character, which causes practical difficulties on the model-based damage detection techniques. This paper presents a novel approach to detect damage in a simply supported beam. In this study, a numerical simulation using the Finite Element Method (FEM) has been done to determine the frequencies to detect the crack in a concrete beam of length $0.12 \mathrm{~m}$ and width $0.015 \mathrm{~m}$. A vibration-based model is employed to simulate the results by using COMSOL Multiphysics. At the tip, by performing the computational analysis it is found that the presence of cracks affects the natural frequencies of the concrete structure. It is observed that after applying load, the frequencies of the cracked beam have been changed with the variation of the location of the crack for all the modes of vibration. It also found that maximum frequency reserved at the cracked point so it will also help us to detect different hidden defects in any structure. A comparison is also made with the experimental results. It is also found that the effect of crack is more near the fixed end than at the free end.
\end{abstract}

\section{Keywords}

Vibration Characteristics, Crack Detection, Modal Analysis, Condition Monitoring, FEM

\section{Introduction}

Identification of structural crack location has gained increasing attentions from 
the scientific and engineering domains since the unpredicted structural failure may cause catastrophic, economic, and life loss [1]. So early detection of these defects seems pivotal for safety and economic reasons, as their detection can remarkably extend the existence of the structure, which increases its reliability at the same time [2]. The most important technique of structural health monitoring is to provide information on the anticipation of structures, simultaneously detects and locates structural fatigue. This needs ideas of the model of structures in great detail, which may not be possible all-time. As we know when a structure suffers from damage, its dynamic property (like as float, string or object) can change and it is observed that crack caused a stiffness reduction in modal natural frequencies. Consequently it results in the change within the dynamic response of the beam [3]. Within the recent years, with the advancement of science and technology, the study of detecting the crack has been increasing among the researchers. Being very commonly utilized in steel construction and machinery industries, health monitoring and thus the analysis of injury within the type of crack within the Beam structures pose a crucial role [4]. Since long efforts are on their to get a feasible solution for crack detection in beam structures, during this regard many approaches have so far being considered. Since there always exist constraints in ferroconcrete structures and buildings deteriorate overtime, cracking seems unavoidable and appears altogether kinds of structures, as an example, concrete wall, and beam, slab, and brick walls. The presence of the crack not only changes the regional stress and strain fields of the crack tip but also effects on structural dynamics [5]. When a structure suffers from damages, its dynamic properties can change. If these fatigues cannot be timely detected and repaired, subsequent fracture can bring catastrophic failure to the beam structures.

Many extensive researches on crack detection in different methods have been performed theoretically and experimentally till today. Kim and Zhao [6] studied a very distinctive crack detection technique employing a harmonic response, where the displacement and slope modes of a cracked cantilever beam are thought of 1st, that the approximate formula for displacement and slope response under single-point harmonic excitation comes. They conclude that the slope response incorporates a pointy amendment with the crack location and additionally the depth of the crack. A new idea has developed by Lee and Chung [7] that how to look out the lowest four natural frequencies of the cracked structure by FEM and additionally the approximate crack location is obtained by exploitation. Later, Owolabi et al. [8] have experimentally investigated of the possessions of cracks and damages on the dependability of structures. An analytical and experimental approach for the fault detection in cantilever beams like structure by vibration analysis has developed by Nahvi [9]. Presently numerous analytical, numerical and experimental techniques are in use for crack detection throughout a fiber-reinforced composite, laminated composites and non-composite structures for its vibration analysis. A numerous vibration based fatigue designation techniques bestowed by Sanjay K. Behera et al. [10] researches for cracked 
composite and non-composite structures. In the same case I. Goda [11], has applied numerical study exploitation finite parts is performed to research the free vibration response of laminated composite beams. They had a tendency to perform dynamic modeling of the laminated beams by associate eigenvalue analysis, exploitation associate eight-node bedded shell part to simulate the free vibrations. The major importance of their study was for the mechanical designer to conceive and optimize composite structures subjected to dynamic loadings [2]. Prasad et al. [12] discussed the effect of location of crack from the free end to the fixed end on crack growth rate along vibrating cantilever beam and a mathematical model was developed using dimensional analysis to find out the value of the crack growth rate along vibrating cantilever beam.

The above papers are studied the changes neighborhood in natural frequencies due to the presence of multiple cracks at intervals associate concrete beam. The target of this paper to look out a method for predicting crack parameters (crack depth associated its location) throughout the concrete beam from changes in natural frequencies. Constant studies are disbursed by using COMSOL Multiphysics software to judge modal parameters (natural frequencies and deflections) for various crack position parameters. The technique developed to detect crack by using the FEM software has become popular in recent years.

\section{Mathematical Modeling}

The vibration-based damage detection has become one of the commonly used tools for crack detection. This approach is mainly based on changes in dynamic characteristics, such as natural frequency and crack position parameter [2]. In this study we consider a Computational domain of a beam, where the dimensions of the beam and crack dimensions are taken from Yamuna and Sambasivarao [13].

\section{Governing Equation}

The equation of motion in matrix form for vibration of a beam under load is given by,

$$
[M]\left\{\frac{\mathrm{d}^{2} q(x)}{\mathrm{d} x^{2}}\right\}+\left[[K]-P\left[K_{g}\right]\right]\{q\}=0
$$

where,

$[M]=$ Consistent mass matrix.

$[K]=$ Bending stiffness matrix of the beam.

$\left[K_{g}\right]=$ Geometric stiffness matrix.

$\{q\}=$ Displacement vector.

$P=$ External force vector.

For free vibration the forcing function $p=0$. So the Equation (1) can be written as,

$$
[M]\left\{\frac{\mathrm{d}^{2} q(x)}{\mathrm{d} x^{2}}\right\}+[K]\{q\}=0
$$


In-plane, the load $P(t)$ can be expressed in the form as shown below,

$$
P(t)=P_{s}+P_{t} \cos \Omega t
$$

where,

$P_{s}=$ the static portion of $P$.

$P_{t}=$ the amplitude of the dynamic portion of $\mathrm{P}$ and

$\Omega=$ the frequency of excitation.

Equation (2) represents an eigen value problem and the roots of the equation give rise to square of the natural frequency given by the equation,

$$
[K]-\left(\omega_{n}\right)^{2}[M]=0
$$

\section{Finite Element Analysis}

In this analysis we consider a beam with two degrees of freedom (slope and deflection) per node [14] which is shown in Figure 1.

The governing equations of a deformation curved beams can be simplified by determining the force, moment, deflection and twist along the fifth metatarsal. This can be done subjected to both a point wise and a distributed load by using Young's Modulus and Moments of Inertia given by the following equation,

$$
\begin{aligned}
& m(x)=\frac{\mathrm{d}^{2} q(x)}{\mathrm{d} x^{2}} E I \\
& V(x)=\frac{\mathrm{d}^{3} q(x)}{\mathrm{d} x^{3}} E I
\end{aligned}
$$

where,

$E=$ Young's Modulus.

$I=$ Moments of Inertia.

The deflection of the beam due to applied loads on the domain are shown in Figure 2.

Now,

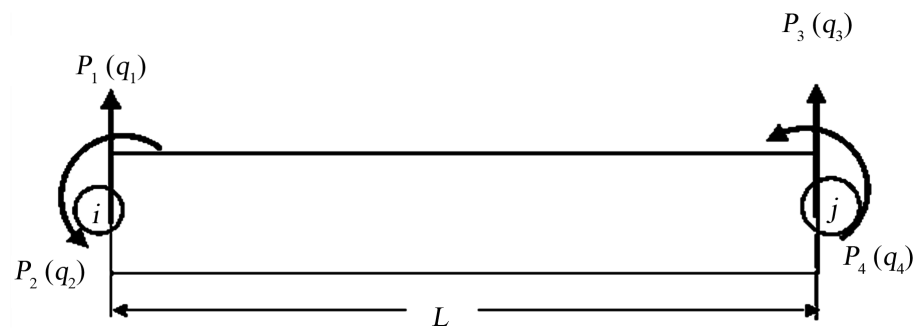

Figure 1. A Two noded beam with two degrees of freedom.

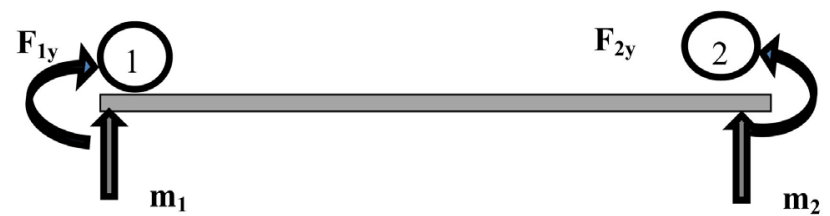

Figure 2. Distribution of loads and deflection of the beam. 


$$
\begin{gathered}
F_{1 y}=V(0)=\frac{\mathrm{d}^{3} q(0)}{\mathrm{d} x^{3}} E I=\frac{E I}{l^{3}}\left(12 q_{1}+6 l \theta_{1}-12 q_{2}+6 l \theta_{2}\right) \\
m_{1}=-m(0)=\frac{\mathrm{d}^{2} q(0)}{\mathrm{d} x^{2}} E I=\frac{E I}{l^{3}}\left(6 l q_{1}+4 l^{2} \theta_{1}-6 l q_{2}+2 l^{2} \theta_{2}\right) \\
F_{2 y}=-V(l)=\frac{\mathrm{d}^{3} q(l)}{\mathrm{d} x^{3}} E I=\frac{E I}{l^{3}}\left(-12 q_{1}-6 l \theta_{1}+12 q_{2}-6 l \theta_{2}\right) \\
m_{2}=-m(l)=\frac{\mathrm{d}^{2} q(l)}{\mathrm{d} x^{2}} E I=\frac{E I}{l^{3}}\left(6 l q_{1}+2 l^{2} \theta_{1}-6 l q_{2}+4 l^{2} \theta_{2}\right)
\end{gathered}
$$

If we write these values in the matrix form of the above system then we find,

$$
\left[\begin{array}{c}
F_{1 y} \\
m_{1} \\
F_{2 y} \\
m_{2}
\end{array}\right]=\left[\begin{array}{cccc}
12 & 6 l & -12 & 6 l \\
6 l & 4 l^{2} & -6 l & 2 l^{2} \\
-12 & -6 l & 12 & -6 l \\
6 l & 2 l^{2} & -6 l & 4 l^{2}
\end{array}\right]\left[\begin{array}{c}
q_{1} \\
\theta_{1} \\
q_{2} \\
\theta_{2}
\end{array}\right]
$$

i.e. The Element stiffness matrix due to bending,

$$
\begin{gathered}
{[K]_{e}=\int_{0}^{L}[B]^{\mathrm{T}}[D][B] \mathrm{d} x} \\
{[K]_{e}=\frac{E I}{l^{3}}\left[\begin{array}{cccc}
12 & 6 l & -12 & 6 l \\
6 l & 4 l^{2} & -6 l & 2 l^{2} \\
-12 & -6 l & 12 & -6 l \\
6 l & 2 l^{2} & -6 l & 4 l^{2}
\end{array}\right]}
\end{gathered}
$$

The stiffness matrix $K_{\text {crack }}$ or $K_{c}$ of a cracked beam element: From equilibrium condition as in Figure 3.

Where,

$$
L_{e}=\left(\begin{array}{cc}
-1 & 0 \\
L_{e} & -1 \\
1 & 0 \\
0 & 1
\end{array}\right)
$$

Hence the stiffness matrix $K_{c r a c k}$ or $K_{c}$ of a cracked beam element can be obtained,

$$
K_{C}=L C_{\text {total }}^{-1} L^{\mathrm{T}}
$$

The cracked element stiffness matrix becomes,

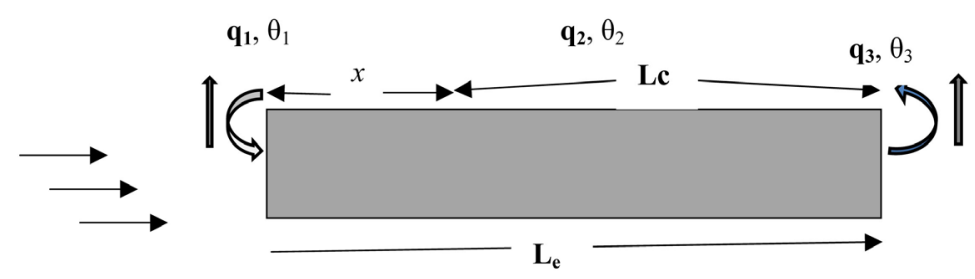

Figure 3. Typical Cracked beam element subject to shearing force and bending moment. 


$$
\left[K_{e}\right]=\frac{1}{C_{11} C_{22}-C_{12} C_{21}}\left[\begin{array}{cccc}
C_{22} & C_{22} L_{e}-C_{21} & -C_{22} & C_{21} \\
C_{22} L_{e}-C_{21} & C_{22} L_{e}^{2}-C_{21} L_{e}-C_{12} L_{e}+C_{11} & -C_{22} L_{e}+C_{12} & -C_{21} L_{e}-C_{11} \\
-C_{22} & -C_{22} L_{e}+C_{21} & C_{22} & -C_{21} \\
C_{12} & C_{12} L_{e}-C_{11} & -C_{12} & C_{11}
\end{array}\right]
$$

\section{Boundary Conditions}

Since two end sided of beam are fixed and no deformation will occur so $q_{1}=\theta_{1}=$ $q_{3}=\theta_{3}=0$. At that point there is no bending moment, shear force so the loading condition $F_{1}=F_{3}=M_{1}=M_{3}=0$. Only the load applied in the middle portion, $F_{2}$ $=500 \mathrm{~N}$ and the bending moment $\mathrm{M}_{2}$ and the cracked position of the beam will remain active.

There are three faces present bounding the calculation domain which are thin Elastic Layer (Boundary 6) is shown in Figure 4.

For Symmetry thin Elastic Layer,

$$
n \cdot u=0
$$

\section{Computational Domain and Mesh Generation}

A design of computational domain without crack \& with crack is shown in Figure 4. The computational domain is considered as a concrete beam domain with length $0.12 \mathrm{~m}$, width $0.015 \mathrm{~m}$ and thickness $0.008 \mathrm{~m}$. The geometry and a suitable mesh are generated by COMSOL Multiphysics Software are shown in Figure 5. To reach a satisfactory computational exactness we continually change the mesh design until the outcomes obtained. The Mesh element becomes higher near the cracked positions have shown in Figure 5(a) and Figure 5(b). While material properties of the computational domain are shown in Table 1 and Table 2. As our domain with defect is complicated thus computer processor capacity becomes a significant issue for the computational study. The finer mesh is used along the whole computational model for numerical simulation. We had used 16 GB DDR3 RAM, Intel core i5 processor based computer for our simulation.

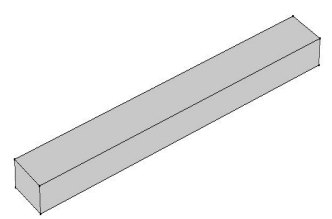

(a)

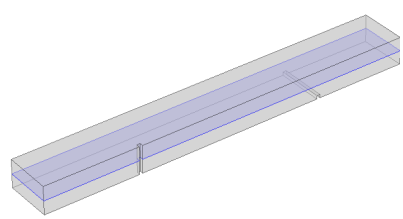

(b)

Figure 4. Computational domain of the concrete beam.

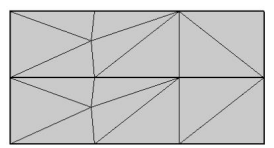

(a)

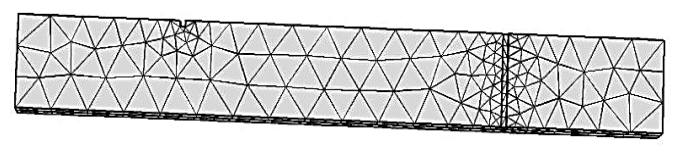

(b)

Figure 5. Mesh design of the computational domain: (a) At the Inlet of the beam; (b) Along the concrete beam. 
Table 1. Mesh properties of the computational domain.

\begin{tabular}{cc}
\hline Description & Value \\
\hline Minimum element quality & 0.2093 \\
Average element quality & 0.6135 \\
Tetrahedron & 1424 \\
Triangle & 863 \\
Edge element & 232 \\
Vertex element & 32 \\
\hline
\end{tabular}

Table 2. Properties of the simulation of computational domain.

\begin{tabular}{cc}
\hline Description & Value \\
\hline Number of degrees of freedom solved for & 10,093 \\
Space dimension & 3 \\
Number of domains & 1 \\
Number of boundaries & 23 \\
Number of edges & 52 \\
Number of vertices & 32 \\
Space dimension & 3 \\
\hline
\end{tabular}

\section{Numerical Results and Discussions}

In this study, we have investigated the frequency of the concrete beam containing double crack using finite element method. For our simulation, we construct a solid concrete beam and have used different parameter values according to Table 3 and Table 4.

In Figure 6 it is shown that a load of $500 \mathrm{~N}$ is applied vertically on the top phase of the concrete beam. Figure 7 shows that the deflection and the phase of the computational domain after applying load. After applying the load, it is found that the load affects the body and frequency variability is observed essentially in the affected area.

Figure 8 shown that different magnitudes of stress applied in the domain and corresponding deflection due to load. It is observed that, after applying load on the beam, a vibration on the structural body is created. The natural frequencies become maximum at the crack position due to the presence of vibration on that point. The maximum portion of load is absorbed in the middle part on the body, so there will be maximum absorption of load on that point. It is also noted that maximum load creates much vibration, which is the major causes to creating crack on any structural body.

Figure 9 shows that the slices of the Load distribution at different crack positions of the domain. We observed the load is maximum at the bottom of the domain. It is also found that the load was applied at the crown edge of the domain and distributed to bottom edge especially at the cracked position with high 


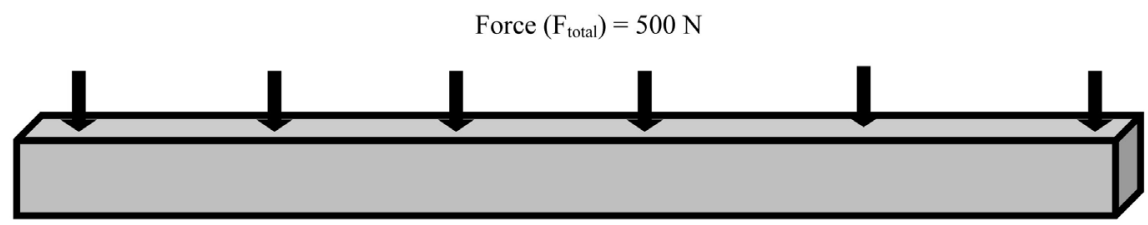

Figure 6. Applying loads on the computational domain.

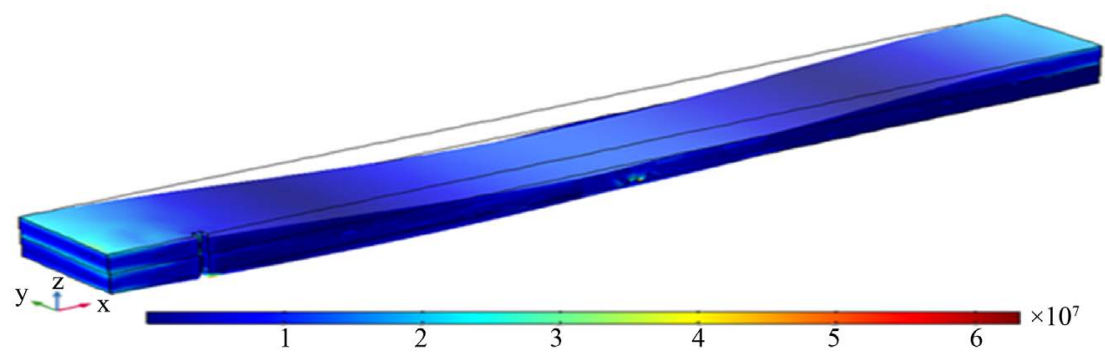

Figure 7. Deflection of the computational domain after applying load.

Table 3. Properties of beam.

\begin{tabular}{cc}
\hline Description & Value \\
\hline Length of the beam (L) & $0.12 \mathrm{~m}$ \\
Width of the beam (h) & $0.015 \mathrm{~m}$ \\
Thickness of the beam (H) & $0.008 \mathrm{~m}$ \\
Depth of First crack (D1) & $0.001 \mathrm{~m}$ \\
Length of First crack (c1l) & $0.001 \mathrm{~m}$ \\
Height of First crack (c1h) & $0.008 \mathrm{~m}$ \\
Depth of the second crack (D2) & $0.017 \mathrm{~m}$ \\
Length of second crack (c2l) & $0.001 \mathrm{~m}$ \\
Height of second crack (c2h) & $0.001 \mathrm{~m}$ \\
\hline
\end{tabular}

Table 4. Properties of material.

\begin{tabular}{cc}
\hline Description & Value \\
\hline Density of concrete & $1570 \mathrm{~kg} / \mathrm{m}^{3}$ \\
Young's modulus & $122.7[\mathrm{GPa}]$ \\
Poisson's ratio & 0.2 \\
Shear modulus & $3.7[\mathrm{GPa}]$ \\
Tensile strength $(\sigma)$ & $2-5 \mathrm{Mpa}$ \\
Shear strength $(\tau)$ & $6-17 \mathrm{MPa}$ \\
\hline
\end{tabular}

vibration and differs the frequency. But there is a difference is formed for the ( $f$ ) that, after the load the beam distorted and deflected. So due to double deflection in this situation, the applied loads distributed into two end sides. Finally we observed that, at the cracked position vibration and frequencies are increased as the load increased and the presence of crack affects the natural frequency of the structure. 


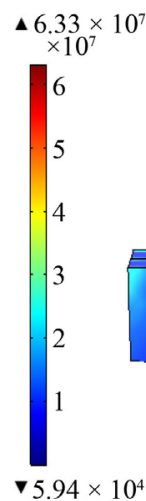

(a)
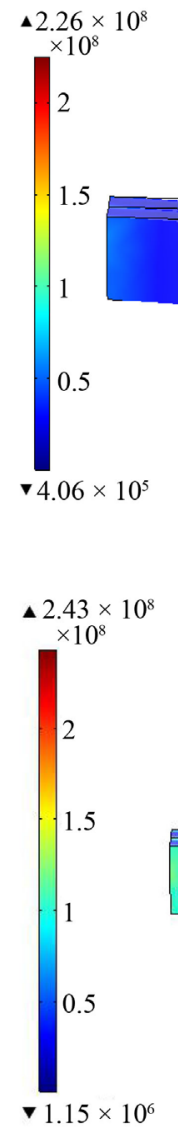

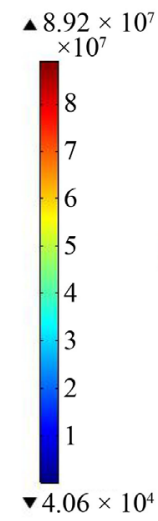

(b)
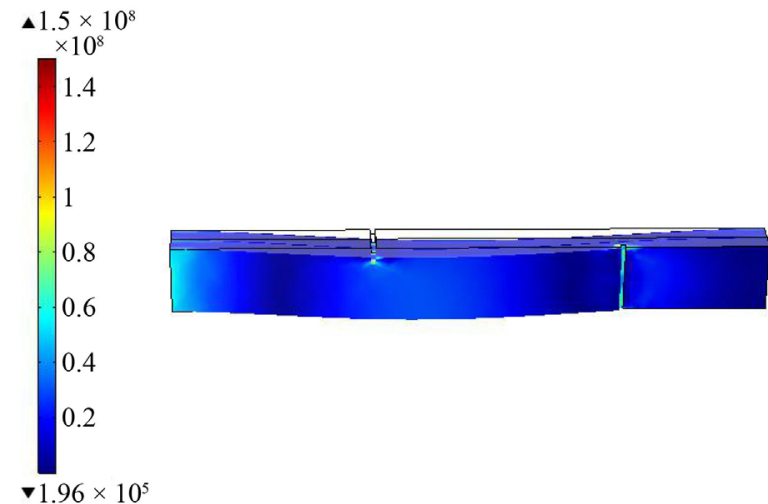

(d) (c)

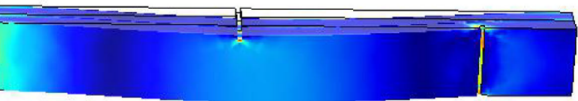

(e)

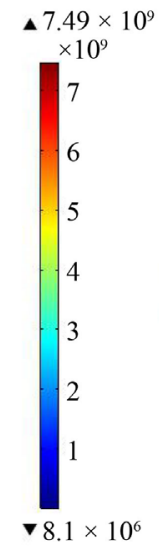

(f)

Figure 8. Load absorbs and Frequency gained in the respective crack position. (a) The position of first crack is at $0.01 \mathrm{~m}$ and second crack is at $0.06 \mathrm{~m}$; (b) The position of first crack is at $0.02 \mathrm{~m}$ and second crack is at $0.07 \mathrm{~m}$; (c) The position of first crack is at $0.03 \mathrm{~m}$ and second crack is at $0.08 \mathrm{~m}$; (d) The position of first crack is at $0.04 \mathrm{~m}$ and second crack is at $0.09 \mathrm{~m}$; (e) The position of first crack is at $0.05 \mathrm{~m}$ and second crack is at $0.10 \mathrm{~m}$; ( $\mathrm{f}$ ) The position of first crack is at $0.06 \mathrm{~m}$ and second crack is at $0.11 \mathrm{~m}$.

Figure 10 shows the line graph of the crack with frequency at different position of this computational domain. It is observed that, the natural frequency graph shows irregularity at the crack positions. According to the graph (a), (b), (c), (d), (e) and (f) we found that, at the respective crack position the graph is fluctuated. So, we can say that at irregular of frequency curve generate the 


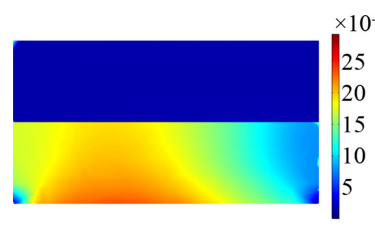

Cut plane slice near the crack

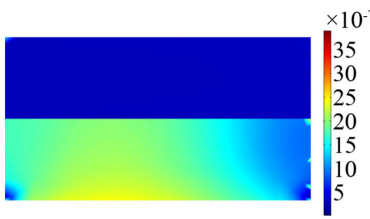

Cut plane slice near the crack

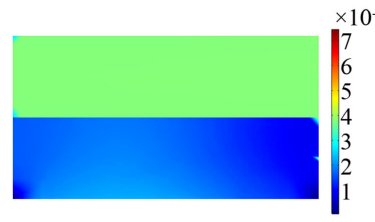

Cut plane slice near the crack

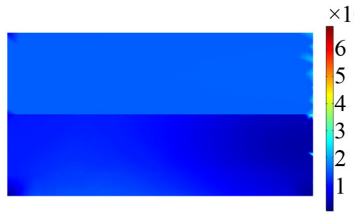

Cut plane slice near the crack

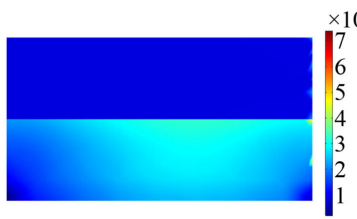

Cut Plane Slice near the crack

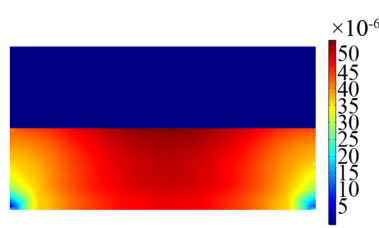

Cut plane slice near the crack

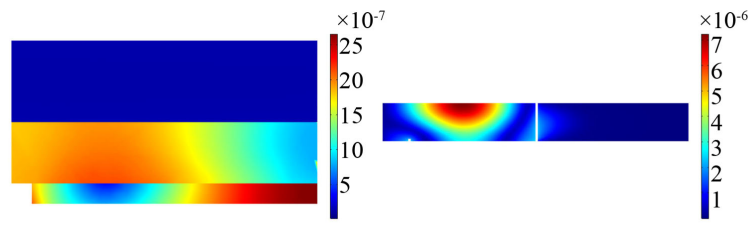

Cut Plane on the crack

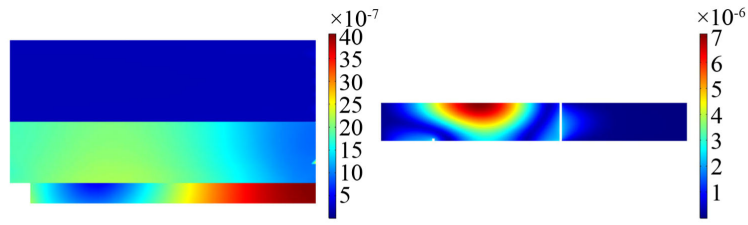

Cut plane on the crack

2D cut plane near the crack

(b)

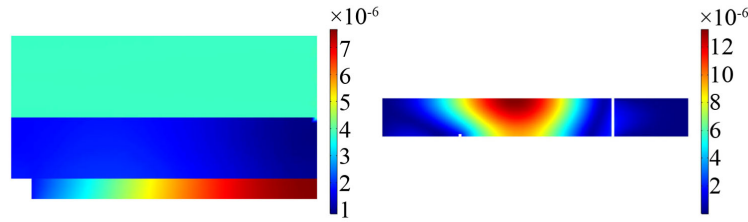

Cut plane on the crack

2D cut plane near the crack

(c)

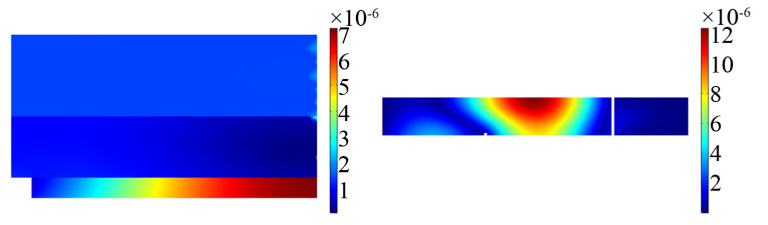

Cut plane on the crack

$2 \mathrm{D}$ cut plane near the crack

(d)

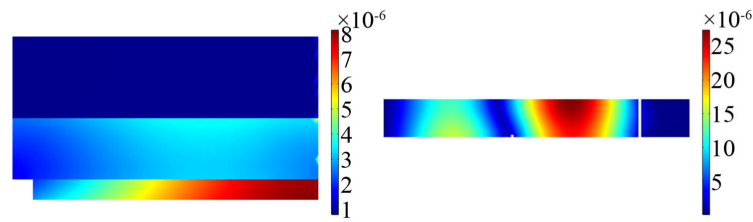

Cut plane on the crack

2D cut plane near the crack

(e)

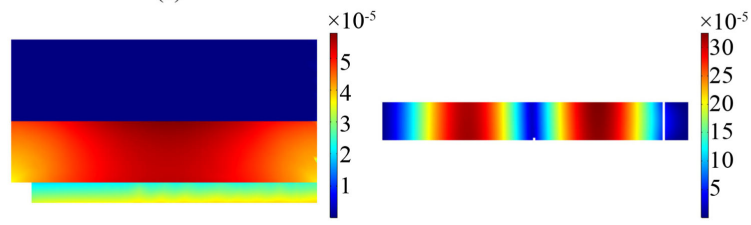

Cut plane on the crack

2D cut plane near the crack

(f)

Figure 9. Slices of the load distributions at different crack position of the domain. (a) The position of first crack is at $0.01 \mathrm{~m}$ and second crack is at $0.06 \mathrm{~m}$; (b) The position of first crack is at $0.02 \mathrm{~m}$ and second crack is at $0.07 \mathrm{~m}$; (c) The position of first crack is at $0.03 \mathrm{~m}$ and second crack is at $0.08 \mathrm{~m}$; (d) The position of first crack is at $0.04 \mathrm{~m}$ and second crack is at $0.09 \mathrm{~m}$; (e) The position of first crack is at $0.05 \mathrm{~m}$ and second crack is at $0.10 \mathrm{~m}$; (f) The position of first crack is at $0.06 \mathrm{~m}$ and second crack is at $0.11 \mathrm{~m}$. 


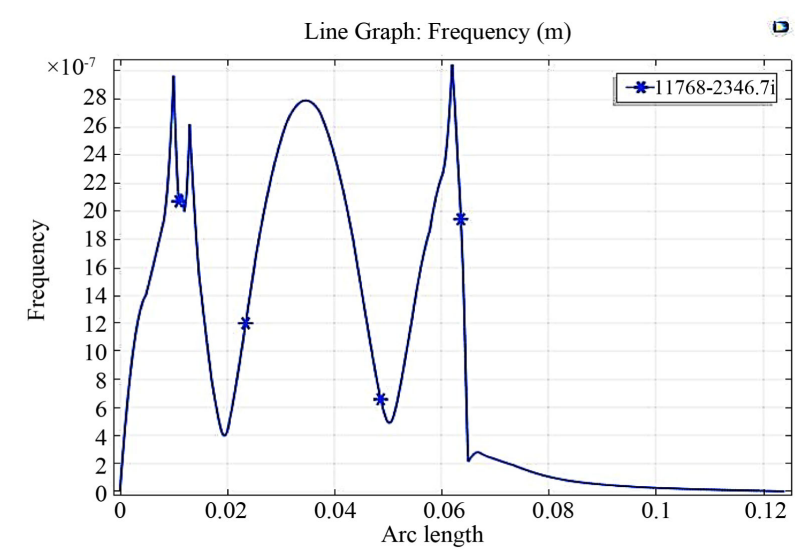

(a)

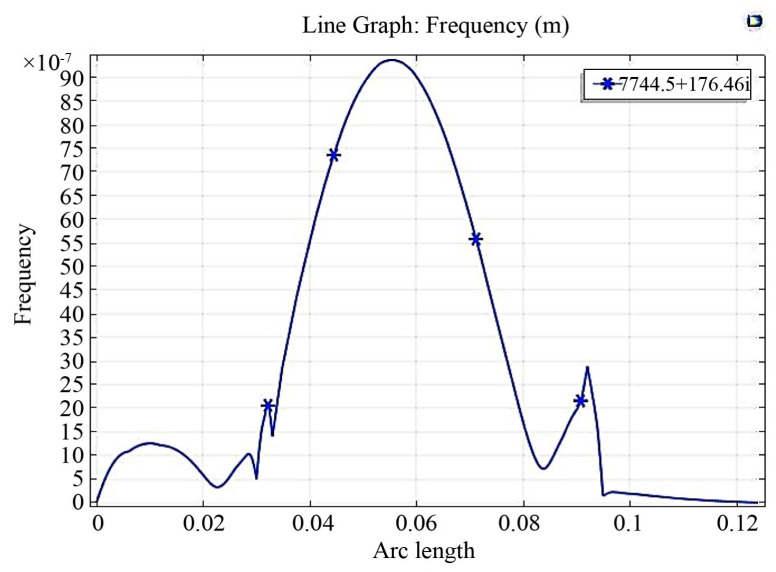

(c)

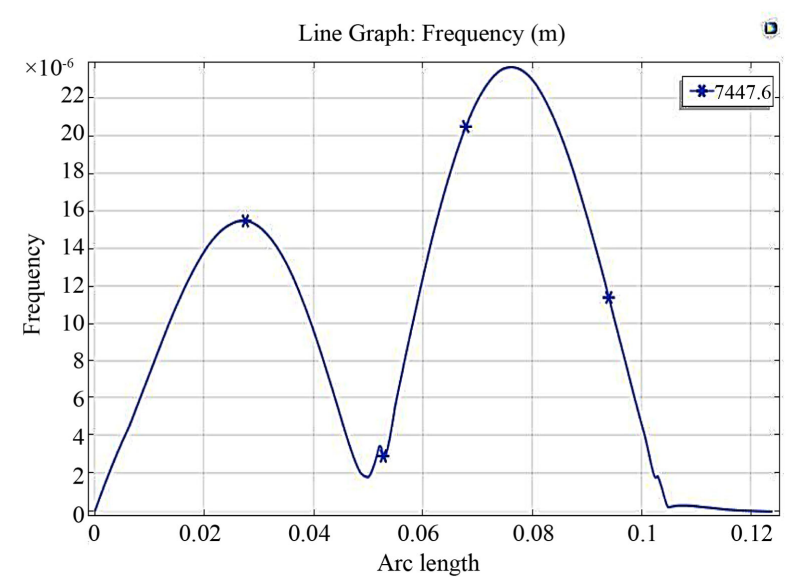

(e)

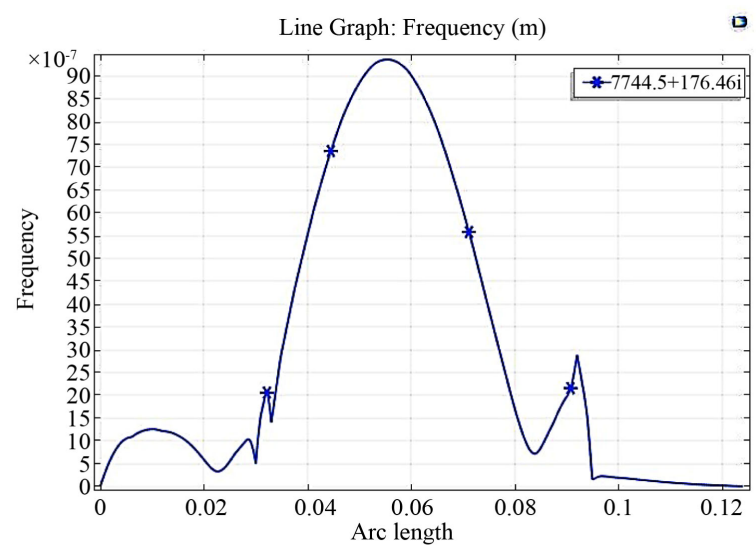

(b)

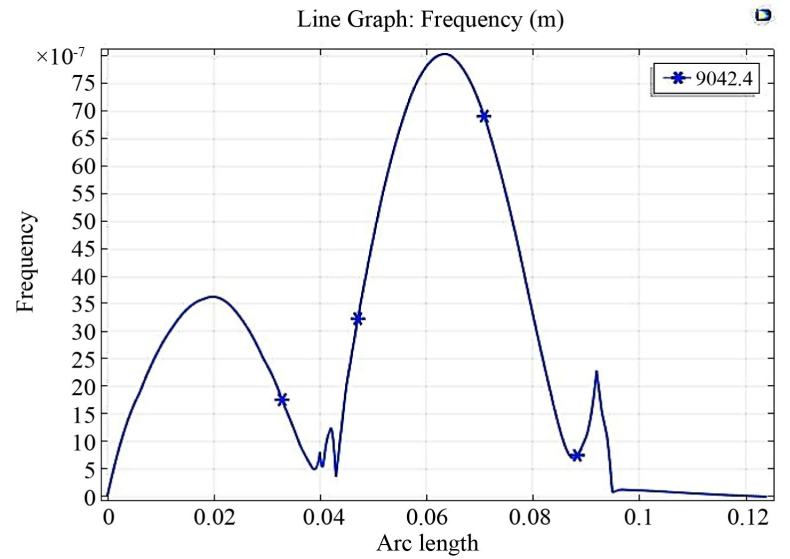

(d)

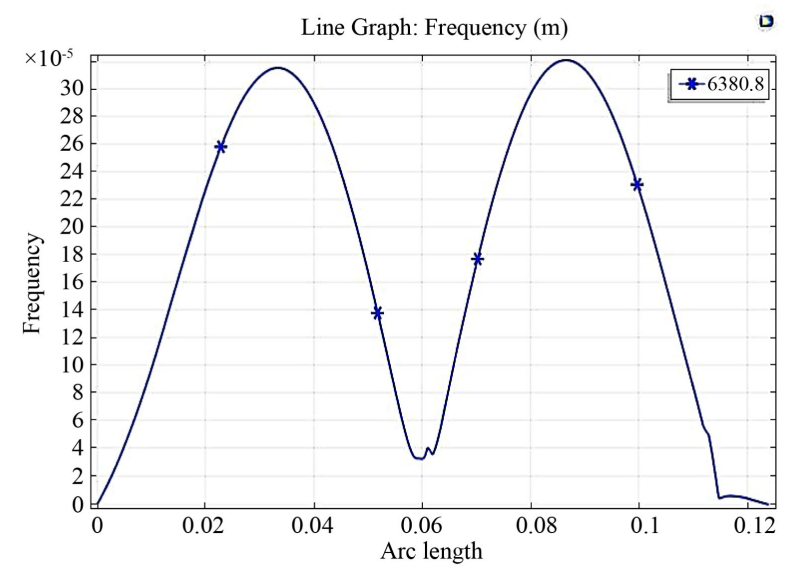

(f)

Figure 10. Line graph of the relative position of crack v/s frequency. (a) The position of first crack is at $0.01 \mathrm{~m}$ and second crack is at $0.06 \mathrm{~m}$; (b) The position of first crack is at $0.02 \mathrm{~m}$ and second crack is at $0.07 \mathrm{~m}$; (c) The position of first crack is at $0.03 \mathrm{~m}$ and second crack is at $0.08 \mathrm{~m}$; (d) The position of first crack is at $0.04 \mathrm{~m}$ and second crack is at $0.09 \mathrm{~m}$; (e) The position of first crack is at $0.05 \mathrm{~m}$ and second crack is at $0.10 \mathrm{~m}$; ( $\mathrm{f}$ ) The position of first crack is at $0.06 \mathrm{~m}$ and second crack is at $0.11 \mathrm{~m}$.

position of crack. It is also seen that as long as the crack changes its position (goes to end points) its frequencies are also increased gradually. Finally from the graph it is clear to us that natural frequencies of the beam are directly affected by the location of the cracks. 


\section{Validation of the Study}

In Table 5 we collect data and tried to compare with the results. According to Figure 11 it is observed that when the position of the crack moves from the fixed end towards the free end of the beam, the effect of the crack also decreases gradually. In order to check the accuracy of the present analysis, we tried to compare our experiment with the experiment done by Priyadarshini A [14] and Kisa et al. [15] the case is considered to validate the program. The presence and position of the crack are typically detected from the comparison of the basic modes of cracked beam. It should be mentioned here that they have used different models and different computational method for their experiments. By comparing with the study of Priyadarshini A [14] and Kisa et al. [15] our results shows an agreement with their results though initially different approach for first two cracks. The analysis was performed on the first six mode shapes. Results of this research on the effectiveness of the damage detection technique applied to higher vibration modes lead to the conclusions that, in practical the presence of crack affects the natural frequency of the structure. The changes of the natural frequency are directly influenced by the different location of the crack.

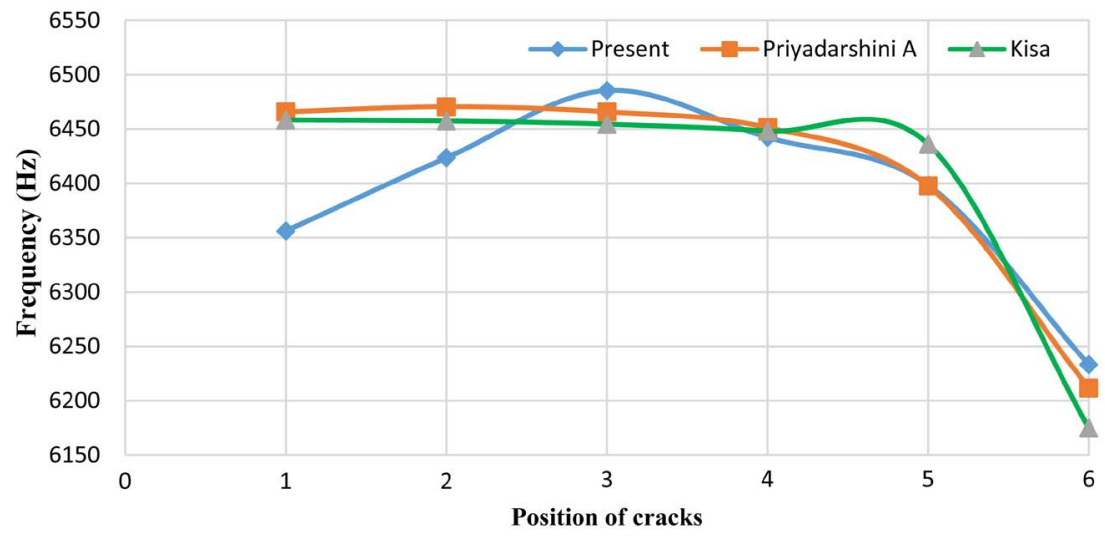

Figure 11. A comparison of the frequencies in different positions of the crack of present analysis with Priyadarshini A [14] and Kisa et al. [15] experiments.

Table 5. Mesh Properties of the computational domain.

\begin{tabular}{ccccccc}
\hline $\begin{array}{c}\text { Serial } \\
\text { no }\end{array}$ & $\begin{array}{c}\text { Difference } \\
\text { between } \\
\text { cracks }(\mathrm{m})\end{array}$ & $\begin{array}{c}\text { Crack } \\
\text { position } \\
\text { of first } \\
\text { crack }(\mathrm{m})\end{array}$ & $\begin{array}{c}\text { Crack } \\
\text { position } \\
\text { of second } \\
\text { crack }(\mathrm{m})\end{array}$ & $\begin{array}{c}\text { Present } \\
\text { analysis FEA } \\
\text { Frequency } \\
(\mathrm{Hz})\end{array}$ & $\begin{array}{c}\text { Priyadarshini } \\
\text { A [14] } \\
\text { Frequency } \\
(\mathrm{Hz})\end{array}$ & $\begin{array}{c}\text { Kisa } \\
\text { et al. [15] } \\
\text { Frequency } \\
\text { (Hz) }\end{array}$ \\
\hline 1st & 0.05 & 0.01 & 0.06 & 6356.1 & 6465.83 & 6458.34 \\
2nd & 0.05 & 0.02 & 0.07 & 6423.6 & 6470.53 & 6457.4 \\
3rd & 0.05 & 0.03 & 0.08 & 6485.5 & 6465.81 & 6454.48 \\
4th & 0.05 & 0.04 & 0.09 & 6442.3 & 6451.41 & 6448.18 \\
5th & 0.05 & 0.05 & 0.10 & 6398.3 & 6397.71 & 6436.01 \\
6th & 0.05 & 0.06 & 0.11 & 6233.2 & 6211.68 & 6174.71 \\
\hline
\end{tabular}




\section{Conclusion}

A numerical simulation is done for a cracked concrete beam with different locations to detect the cracks. The flexibility matrix method is used to calculate the stiffness of the cracked beam by using FEM based vibration model using COMSOL Multiphysics [16]. In this study it is observed that, the frequencies of the cracked beam have been changed with the change of the location of the crack for all the modes of vibration. The effect of crack is higher at near the fixed end than at the free end. From our simulation it is found that the frequencies increase proportional to load distribution and at cracked position the body gets much frequency. Finally we come to the conclusion that the presence of crack and different amounts of loads has a great influence on changing the mode shapes and frequencies of beam. The results confirm that detection of crack size, crack location in a concrete beam depends on natural frequencies and mode shapes. For the established curvature function, if the load is higher, the value of the curvature modulus is also higher, which indicates that higher modes are more sensitive to the presence of the defect. In future our model can be used for crack inclination and different depths.

\section{Acknowledgements}

The authors gratefully acknowledge for the technical support to the Centre of excellence in Mathematics, Department of Mathematics, Mahidol University, and Bangkok, Thailand. The authors also acknowledge to the Simulation Lab, Department of Mathematics, Chittagong University of Engineering and Technology, Bangladesh, for the support to complete this research.

\section{Conflicts of Interest}

The authors declare no conflicts of interest regarding the publication of this paper.

\section{References}

[1] Dimarogonas, A.D. (1996) Vibration of Cracked Structures: A State of the Art Review. Engineering Fracture Mechanics, 55, 831-857. https://doi.org/10.1016/0013-7944(94)00175-8

[2] Liu, W. and Barkey, M.E. (2017) Nonlinear Vibrational Response of a Single Edge Cracked Beam. Journal of Mechanical Science and Technology, 31, 5231-5243. https://doi.org/10.1007/s12206-017-1016-1

[3] Fan, W. and Qiao, P.Z. (2010) Vibration-Based Damage Identification Methods: A Review and Comparative Study. Structural Health Monitoring, 10, 83-111. https://doi.org/10.1177/1475921710365419

[4] Jena1, P., Dayal, R.P. and Goutam, P. (2012) Faults Detection of a Single Cracked Beam by Theoretical and Experimental Analysis Using Vibration Signatures. IOSR Journal of Mechanical and Civil Engineering (IOSR-JMCE), 4, 1-18. https://doi.org/10.9790/1684-0430118 http://www.iosrjournals.org/ 
[5] Yang, D.L., Yiu, Y.L., Li, S.B., Tao, J., Liu, C. and Liu J.H. (2017) Fatigue crack Growth Prediction of 7075 Aluminum Alloy Based on the GMSVR Model Optimized by the Artificial Bee Colony Algorithm. Engineering Computations, 34, 1034-1053. https://doi.org/10.1108/EC-11-2015-0362

[6] Kim, M.-B. and Zhao, M. (2004) Study on Crack Detection of Beam Using Harmonic Responses. Proceedings of the 2004 International Conference on Intelligent Mechatronics and Automation, 26-31 August 2004, Chengdu, 72-76.

[7] Young, M.S.L. and Chung, J. (2000) A Study on Crack Detection Using Eigen Frequency Test Data Computers and Structures, 77, 327-342. https://doi.org/10.1016/S0045-7949(99)00194-7

[8] Owolabi, G.M., Swamidas, A.S.J. and Seshadri, R. (2003) Crack Detection in Beams Using Changes in Frequencies and Amplitudes of Frequency Response Functions. Journal of Sound and Vibration, 265, 1-22. https://doi.org/10.1016/S0022-460X(02)01264-6

[9] Nahvi, H. and Jabbari, M. (2005) Crack Detection in Beams Using Experimental Modal Data and Finite Element Model. International Journal of Mechanical Sciences, 47, 1477-1497. http://www.elsevier.com/locate/ijmecsci https://doi.org/10.1016/j.ijmecsci.2005.06.008

[10] Behera, S.K., Agarwalla, D.K., Parhi, D.R. and Das, H.C. (2012) Vibration Analysis of a Cracked Composite Beam Using Various Techniques-A Review. IJAICR, 4, 95-101.

[11] Goda, I., Ganghoffer, J.F. and Aly, M.F. (2012) Parametric Study on the Free Vibration Response of Laminated Composite Beams. 1st International Conference on Mechanics of Nano, Micro and Macro Composite Structures, Politecnico di Torino, 18-20 June 2012, 18-20.

[12] Prasad, H.K. and Kumar, M.S. (2009) Studies on Effect of Change in Dynamic Behavior of Crack Using FEM. International Journal of Recent Trends in Engineering, 1, 137-141.

[13] Yamuna, P. and Sambasivarao, K. (2014) Vibration Analysis of Beam with Varying Crack Location. International Journal of Engineering Research and General Science, 2, 1008-1017.

[14] Priyadarshini, A. (2013) Identification of Cracks in Beams Using Vibrational Analysis. Thesis of Master of Technology in Structural Engineering, Department of Civil Engineering, National Institute of Technology, Rourkela.

[15] Kisa, M., Brandon, J. and Topcu, M. (1998) Free Vibration Analysis of Cracked Beams by a Combination of Finite Elements and Component Mode Synthesis Methods. Computers \& Structures, 67, 215-223. https://doi.org/10.1016/S0045-7949(98)00056-X

[16] Comsol Multiphysics. http://www.comsol.com 